J. Lake Sci. (湖泊科学), 2013, 25(2):277-282

http: //www. jlakes.org. E-mail : jlakes@niglas.ac.cn

(C) 2013 by Journal of Lake Sciences

\title{
营养盐对微囊藻细胞组分及多糖组成的影响”
}

\author{
代晓炫 ${ }^{1}$, 朱 伟 ${ }^{1,2}$, 李 明 ${ }^{1}$ \\ ( 1 : 河海大学环境学院,南京 210098$)$ \\ $(2$ : 水资源高效利用与工程安全国家工程研究中心, 南京 210098)
}

\begin{abstract}
摘 要: 胞外多糖是微囊藻形成群体的物质基础, 营养盐是否会通过影响微囊藻多糖的含量进而影响群体的形成还不清 楚. 在室内培养实验中, 设置不同 N、P 浓度的培养液并测定对数期胞内的细胞组分以及 3 种形态的多糖含量, 从而探讨 $N 、 P$ 对细胞中多糖的影响规律. 实验结果表明: RNA 在细胞中的含量相对恒定 (约 $2.0 \mathrm{pg} / \mathrm{cell}$ ). N 对单细胞的蛋白质和 多糖都产生了显著影响: $\mathrm{N}$ 浓度的升高显著促进蛋白质的合成, 细胞中总糖的含量降低. $\mathrm{P}$ 浓度的升高同样造成细胞中多 糖总量减少, 但其对蛋白质影响不大(在 $4.6 \mathrm{pg}$ / cell 左右波动). $\mathrm{N}$ 浓度的增加还促进多糖向胞外分泌并溶解于培养基 中. 在高生长率下, 由于细胞中 RNA、蛋白质的合成速度加快, 多糖的合成较慢导致胞外固着性多糖减少, 这可能是室内 培养难以得到群体的原因之一.
\end{abstract}

关键词: 微囊藻;多糖;蛋白质;RNA

\section{Effect of nutrients on components and polysaccharide content of Microcystis cells}

\author{
DAI Xiaoxuan ${ }^{1}$, ZHU Wei $^{1,2} \&$ LI Ming ${ }^{1}$ \\ (1: College of Environment, Hohai University, Nanjing 210098, P. R. China) \\ (2: National Engineering Research Center of Water Resources Efficient Utilization and Engineering Safety, Nanjing 210098, \\ P. R. China)
}

\begin{abstract}
A laboratory experiment was conducted to study the influence of nutrients (nitrogen and phosphorus) on the component of Microcystis cells ( polysaccharide, protein, and RNA). These biochemical parameters were analyzed during the logarithmic phase. Results showed that the concentrations of $\mathrm{N}$ and $\mathrm{P}$ had limited effect on the content of RNA, which was relatively constant in each cell (about $2.0 \mathrm{pg} /$ cell). However, the cellular contents of protein and polysaccharide were significantly affected by the $\mathrm{N}$ concentrations. The protein content was notably increased with the increase of $\mathrm{N}$ concentration, and the total polysaccharide content remarkably decreased on the contrary. The influence of $\mathrm{P}$ concentration on the total polysaccharide content was similar to that of $\mathrm{N}$ concentration, however, it showed little effects on protein content (nearly $4.6 \mathrm{pg} / \mathrm{cell}$ ). The increase of $\mathrm{N}$ concentration could also promote intracellular polysaccharide (IPS) transform to extracellular polysaccharide (EPS), and the soluble part of EPS increased. Besides, the RNA and protein were rapidly synthesized when cells were in high growth rate, which caused the polysaccharide synthesis was too slow to produce enough extracellular polysaccharide for colony formation. Thus, it was difficult to form colonies during the laboratory incubation.
\end{abstract}

Keywords: Microcystis; polysaccharide; protein; RNA

我国湖泊、水库富营养化严重, 蓝藻水华频繁发生. 在各种类型的水华暴发实例中, 微囊藻属 (Microcys$t i s$ ) 是最为常见的水华藻类之一. 湖泊的实际调查表明, 湖泊中的微囊藻一般是由少则几十上百个, 多则成 千上万的细胞形成的群体赋存 ${ }^{[1-2]}$, 在暴发期, 能看到明显的颗粒状、絮团状的微囊藻群体漂浮聚集在水体 表面. 群体的形成使微囊藻更容易克服风浪扰动从而上浮聚集 ${ }^{[3]}$, 也能够避免被水蚤、轮虫等浮游动物大量 捕食 ${ }^{[4]}$, 这可能是微囊藻水华形成的关键因素之一. 然而在实际湖泊中以群体出现的微囊藻, 在室内的培养

* 江苏省重点基金项目 (BK2011025) 和江苏省水利科技项目(2011069)联合资助. 2012-06-18 收稿;2012-09-03 收修改稿. 代晓炫,女,1988 年生, 硕士研究生;E-mail : zhuweiteam. hhu@ gmail. com. 
试验中, 却很难出现类似野外的大群体. 虽然有很多研究讨论浮游动物捕食, 微生物以及环境条件对群体形 成的影响,但形成群体的物质机制还不够清晰.

一般认为微囊藻形成群体的物质基础是细胞外由多糖构成的胶鞘组织. Martin 等 ${ }^{[5]}$ 通过染色在电镜下 观察到边缘微囊藻 (Microcystis marginata) 在形成群体的过程中胞外有胶被存在, 同时认为群体是由胶被包 裹新分裂的细胞而形成. Plude 等 ${ }^{[6]}$ 对水华微囊藻的胶被成分进行了分析, 明确了这层胶被的主要成分为多 糖类化合物, 称之为 EPS. De Philippis 等 ${ }^{[7]}$ 认为 EPS 能够影响细胞表面的厚度, 并能导致藻的团聚. Yang 等 ${ }^{[8]}$ 于 2008 年发现在鞭毛虫的捕食压力下铜绿微囊藻会形成小群体, 同时总多糖和胞外多糖都有增多. Liu 等 ${ }^{[9]}$ 则发现在添加乙醛酸的处理下, 栅藻的总糖增加且和群体的细胞个数呈正相关性. 可见, EPS 是微囊藻 群体形成的物质基础, 是直接影响微囊藻是否形成群体形态的关键物质. 而其他因素对群体形成的影响首 先通过影响细胞 EPS 的多少, 从而对群体形态产生影响. 那么, 微囊藻在细胞生长分裂过程中 EPS 是如何产 生的, 又受到什么因素的影响而成为备受关注的问题. 2005 年张晓峰等 ${ }^{[10]}$ 调查了从春初到夏季太湖微囊藻 复苏的过程, 初春季节未见微囊藻胶被存在, 但随着时间推移, 微囊藻细胞外面出现明显的胶被并聚成较大 的藻团, 到夏季暴发期微囊藻细胞胶被物质即多糖的增多而形成大群体聚集到湖水表面. 但微囊藻 EPS 增 加过程中环境条件的影响并不清楚.

蓝藻细胞通过光合作用合成碳水化合物,然后根据生理活动的需要合成核酸、蛋白质、多糖及酯类等. 单个细胞中多糖的多少实际上取决于多糖与微囊藻细胞内蛋白质、核酸等物质的比例关系. 在细胞分裂过 程中与多糖合成有关的物质主要是 $\mathrm{C} 、 \mathrm{H} 、 \mathrm{O}$, 而在自然水体中 $\mathrm{C} 、 \mathrm{H} 、 \mathrm{O}$ 都是充足的, 因此这 3 种物质不会成为 多糖合成的限制因素. 一些研究证实 $N$ 的多少直接影响藻类蛋白质的合成量, 而核酸的合成受到 N、P 的影 响 ${ }^{[1-13]}$, 且核酸中的 RNA 会影响蛋白质的合成. 因此微囊藻生存环境中 N、P 的含量变化, 可能会通过藻细 胞中蛋白质、RNA 的含量而影响多糖在单细胞生物量中的比例, 从而对能否产生足够的胶鞘组织而形成群 体发生影响. 施军琼等 ${ }^{[14]}$ 在 2008 年研究了多种环境因子对铜绿微囊藻多糖产量的影响, 认为略低的 N 浓度 会提高总糖含量, 而较高的 $\mathrm{N}$ 浓度则降低了其总糖的含量但提高了 EPS 的合成, 其实验结果只反映了单位 体积藻液的产率变化, 与藻密度的影响有关. 雷腊梅等 ${ }^{[15]}$ 在 2007 年研究了 N、P、S、Fe、EDTA 对胞外多糖产 生的影响, 认为 N、P 都会刺激 EPS 的产生, 其他营养条件的改变对 EPS 的影响不大, 但是其研究只单独关注 了藻细胞溶出的多糖量所受到的影响.

从 N、P 浓度会影响蛋白质、RNA 的数量从而影响多糖在细胞中的比例这一基本认识出发, 本研究通过 改变 $\mathrm{N} 、 \mathrm{P}$ 浓度进行铜绿微囊藻的培养实验, 测定微囊藻细胞的蛋白质、RNA、多糖的含量及 3 种形态多糖的 含量的变化. 探讨 N、P 浓度对细胞中多糖比例及形态的影响以及其影响机理.

\section{1 材料与方法}

\section{1 培养方法及实验参数}

培养实验参照常用的方法. 实验所用铜绿微囊藻 (FACHB-469) 购自中国科学院武汉水生生物研究所, 采用 M11 培养基( $100 \mathrm{mg} \mathrm{NaNO} 、 10 \mathrm{mg} \mathrm{K} \mathrm{HPO}_{4} 、 75 \mathrm{mg} \mathrm{\textrm {MgSO } _ { 4 }} \cdot 7 \mathrm{H}_{2} \mathrm{O} 、 40 \mathrm{mg} \mathrm{CaCl} \cdot 2 \mathrm{H}_{2} \mathrm{O} 、 20 \mathrm{mg} \mathrm{Na} \mathrm{CO}_{3}$ 、 $6 \mathrm{mg}$ 柠檬酸铁和 $1 \mathrm{mg} \mathrm{Na} \mathrm{EDTA}_{2} \cdot 2 \mathrm{H}_{2} \mathrm{O} 、 1 \mathrm{~L}$ 蒸馏水), 使用 $250 \mathrm{ml}$ 的雉形瓶 ( $150 \mathrm{ml}$ 培养基), 温度为 $25^{\circ} \mathrm{C}$, 光照强度为 $3000 \mathrm{~lx}$, 每天摇瓶 3 次并随机调换雉形瓶的位置以保证光照均匀. 光暗比为 $12 \mathrm{~h}: 12 \mathrm{~h}$, 初始接种 密度为 $10 \times 10^{4} \mathrm{cells} / \mathrm{ml}$, 整个培养过程均保持无菌操作.

实验设置了 $\mathrm{N}$ 控制组和 $\mathrm{P}$ 控制组, 每组 5 个浓度梯度, 各 3 个平行. $\mathrm{N}$ 控制组在 M11 培养基的基础上通 过添加或减少 $\mathrm{NaNO}_{3}$ 来改变 $\mathrm{N}$ 的浓度, 实验梯度为: 3.29、8.24、16.47 (原 $\mathrm{M} 11$ 培养基浓度)、32.94、 $82.35 \mathrm{mg} / \mathrm{L} . \mathrm{P}$ 控制组在 $\mathrm{M} 11$ 培养基的基础上通过添加或减少 $\mathrm{K}_{2} \mathrm{HPO}_{4}$ 来改变 $\mathrm{P}$ 的浓度, 实验梯度为: $0.18 、 0.36 、 0.89 、 1.78$ (原 M11 培养基浓度) 、 $3.56 \mathrm{mg} / \mathrm{L}$.

\section{2 测定指标及方法}

通过预实验可知, 各组培养实验进行到第 $8 \mathrm{~d}$ 时, 细胞都会处于对数生长期. 此次实验以对数生长期的 细胞为对象, 因此取第 $8 \mathrm{~d}$ 的藻样进行测定. 测定指标有: 藻细胞密度、3 种形态多糖含量、细胞中的蛋白质 含量、RNA 含量. 
藻细胞密度及生长率的计算: 藻细胞密度与藻液吸光度之间存在显著线性相关关系 ${ }^{[16]}$, 用分光光度计 (岛津 UV-2450) 对原藻种进行了 $400 \sim 800 \mathrm{~nm}$ 吸收扫描, 确定本藻种的最大吸收波峰为 $680 \mathrm{~nm}$, 建立藻细 胞密度与吸光度之间的关系曲线: 生物量 $\left(10^{6} \mathrm{cells} / \mathrm{ml}\right)=24.693 A_{680}-0.3282\left(R^{2}=0.9982\right)$. 在试验所采用 的培养基 $\mathrm{N} 、 \mathrm{P}$ 浓度范围内培养藻液对这一关系曲线进行验证, 其线性关系稳定. 因此, 藻细胞密度可通过测 定吸光度后用此关系曲线换算获得. 生长率 $(\mu)$ 可通过对数生长曲线 $\mu=\ln \left(N_{2} / N_{1}\right) /\left(t_{2}-t_{1}\right)$ 计算得到, 其 中, $N_{1} 、 N_{2}$ 为时间 $t_{1} 、 t_{2}$ 下的藻密度.

多糖的测定: 针对多糖的类型, Yang 等 ${ }^{[8]}$ 把多糖分为胞内多糖 IPS、固着性胞外多糖 bEPS 和溶解性胞 外多糖 sEPS. 本次实验也采用此分类方法对 3 种不同类型的多糖进行测定. 取藻液 $20 \mathrm{ml}$, 在 10500 转 $/ \mathrm{min}$ 离心 $15 \mathrm{~min}$ 使藻液分离, 取上清液测定溶解性胞外多聚糖 sEPS. 上述离心后的藻团加人 $10 \mathrm{ml}$ 去离子水, 再 加人 $0.5 \mathrm{~mol} / \mathrm{L} \mathrm{NaOH}$ 溶液调节 $\mathrm{pH}$ 为 10 , 摇匀后置于水浴震荡器中, $45^{\circ} \mathrm{C}$ 温水震荡 $4 \mathrm{~h}$, 然后 10500 转 $/ \mathrm{min}$ 离心 $15 \mathrm{~min}$, 上清液用于测定固着性胞外多聚糖 bEPS. 第二次离心后的藻团加 $0.5 \mathrm{~mol} / \mathrm{L} \mathrm{NaOH}$ 后沸水浴 $10 \mathrm{~min}$ 使胞内多聚糖溶解出来, 加人体积分数 $17 \%$ 的三氯乙酸沉淀色素和蛋白, 在 10500 转 $/ \mathrm{min}$ 离心 $15 \mathrm{~min}$, 上清液用于测定胞内多聚糖 IPS 含量. 取上述 3 次的滤液各 $2 \mathrm{ml}$ 用葱酮法测定多聚糖含量. 最后根 据藻细胞密度的实测值可计算出单细胞所含胞外多聚糖 EPS 和胞内多聚糖 IPS 的量.

细胞中蛋白质、RNA 含量测定: 取 $10 \mathrm{ml}$ 藻液测定其 TC 值, 将剩余的藻液离心, 用冷冻干燥的方法除去 细胞中水分, 得到干藻样, 便于保存待测定蛋白质及 RNA. 用元素分析仪得到干藻样中的 C 含量, 对藻液 TC 浓度与干藻样的 TC 含量进行换算, 以得到藻细胞的平均干重. 取一定质量的干藻样, 加 $0.5 \mathrm{~mol} / \mathrm{L} \mathrm{NaOH}$ 溶 液, 先用冻融法初步破碎细胞, 再于 $100^{\circ} \mathrm{C}$ 恒温水浴 $10 \mathrm{~min}$ 提取, 离心后用考马斯亮蓝法测定蛋白质含量. 取 一定质量的干藻样, 加 $10 \%$ 高氯酸溶液, 冻融后于 $90^{\circ} \mathrm{C}$ 恒温水浴 $30 \mathrm{~min}$, 离心后再重复上述提取过程, 两次 的离心液合并后用地衣酚显色法测定 RNA 含量. 使用二苯胺法对提取液中的 DNA 进行测定, 测得提取液中 DNA 含量极低, 因此未对 RNA 含量进行修正.

\section{2 结果}

\section{1 微囊藻的细胞密度与生长率}

对处于对数生长期, 培养至第 $8 \mathrm{~d}$ 时, $\mathrm{N} 、 \mathrm{P}$ 两组实验的藻细胞密度及生长率进行整理 (图 1). 随着 $\mathrm{N}$ 浓度 的升高, $\mathrm{N}$ 组的藻细胞密度从 $760 \times 10^{4}$ cells $/ \mathrm{ml}$ 升至 $965 \times 10^{4} \mathrm{cells} / \mathrm{ml}$, 生长率从 $0.54 \mathrm{~d}^{-1}$ 增加到 $0.57 \mathrm{~d}^{-1}$; $\mathrm{P}$ 组的藻细胞密度在 $595 \times 10^{4} \sim 811 \times 10^{4} \mathrm{cells} / \mathrm{ml}$ 范围之间变化, 随着 $\mathrm{P}$ 浓度的升高, 其藻细胞密度开始时 不断升高, 但当 $\mathrm{P}$ 浓度超过 $1.8 \mathrm{mg} / \mathrm{L}$ 后, 到第 5 组其生物量下降, 对应的生长率从 $0.51 \mathrm{~d}^{-1}$ 升至 $0.55 \mathrm{~d}^{-1}$ 再 降至 $0.54 \mathrm{~d}^{-1}$.
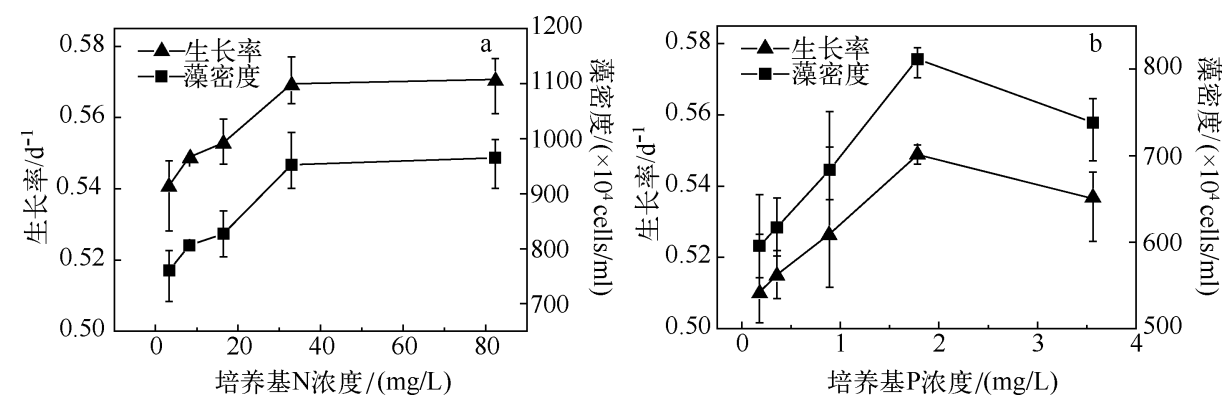

图 $1 \mathrm{~N}$ 组 $(\mathrm{a})$ 和 $\mathrm{P}$ 组 $(\mathrm{b})$ 的生长率和藻细胞密度

Fig. 1 Growth rate and algal cell density of different $\mathrm{N}(\mathrm{a})$ and $\mathrm{P}(\mathrm{b})$ groups

\section{2 细胞中蛋白质、RNA、总糖含量的变化}

使用细胞密度、单细胞的干重和实测各物质的总量进行计算, 可以得到平均单细胞中蛋白质、RNA 和总 糖( TPS) 的含量 (图 2). 微囊藻细胞中蛋白质的含量最高, RNA 含量一般只有蛋白质的一半以下. 总糖含量 最低,一般是细胞质量的 $10 \%$ 左右. 
在 $\mathrm{N}$ 发生改变的 $\mathrm{N}$ 组, 蛋白质含量明显随着 $\mathrm{N}$ 含量的升高而升高, 从 $3.63 \mathrm{pg} /$ cell 增至 $5.88 \mathrm{pg} / \mathrm{cell}$; RNA 含量则基本不发生变化, 保持在 $1.9 \sim 2.2 \mathrm{pg} / \mathrm{cell}$ 之间; 总糖含量则随着 $\mathrm{N}$ 的增加明显减少, 从 $0.87 \mathrm{pg} /$ cell降至 $0.78 \mathrm{pg} / \mathrm{cell}$,减少 10\%（图 2a).

在 P 发生改变的 P 组, 蛋白质含量变化不大, 基本保持在 $4.40 \sim 4.83 \mathrm{pg} / \mathrm{cell}$ 之间; RNA 含量也没有发 生显著变化; 只有总糖随着 $\mathrm{P}$ 的升高有明显的下降趋势 (图 $2 \mathrm{~b}$ ).
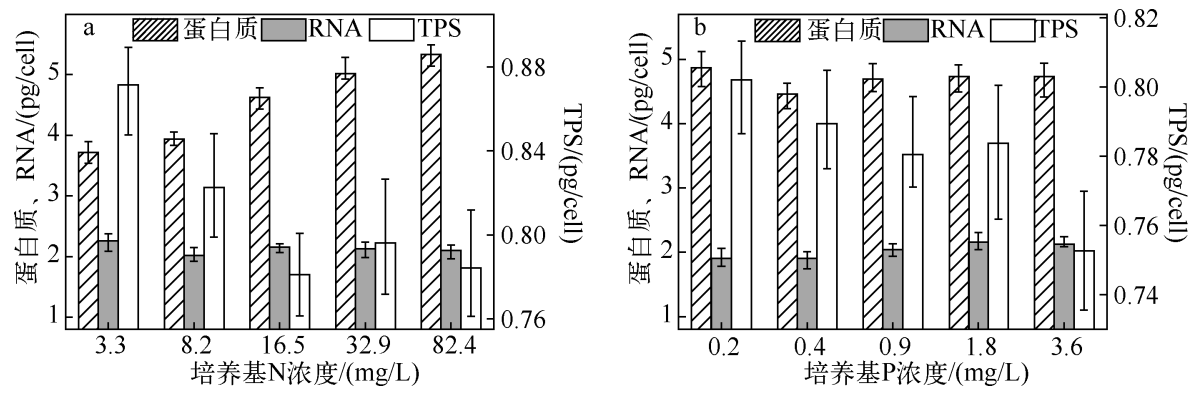

图 $2 \mathrm{~N}$ 组 $(\mathrm{a})$ 和 $\mathrm{P}$ 组 $(\mathrm{b})$ 的细胞中蛋白质、RNA、总糖含量的变化

Fig. 2 Changes in the contents of protein, RNA and TPS in cells of different $\mathrm{N}(\mathrm{a})$ and $\mathrm{P}(\mathrm{b})$ groups

\section{3 多糖与蛋白质、RNA 之间的比例关系}

TPS 与蛋白质的比值及 RNA 比值, 可以反映细胞中多糖的含量与蛋白质、RNA 之间的比例关系, 结果 可以看出,随着 N、P 的增加, TPS/蛋白质或 TPS/RNA 都呈现减少的趋势 (图 3).

$\mathrm{N}$ 组的 TPS/蛋白质的值随 $\mathrm{N}$ 浓度升高一直下降, 从 0.237 下降至 0.147 ; TPS/RNA 的比值则有所波动, 但总体仍在 $0.362 \sim 0.408$ 之间表现出下降趋势 (图 3a). P 组的 TPS/蛋白质的比值则有所波动, 但基本在 0.16 0.17 之间呈下降趋势; 而 TPS/RNA 值随着 P 浓度的升高一直下降, 从 0.421 下降至 0.354 (图 3b).
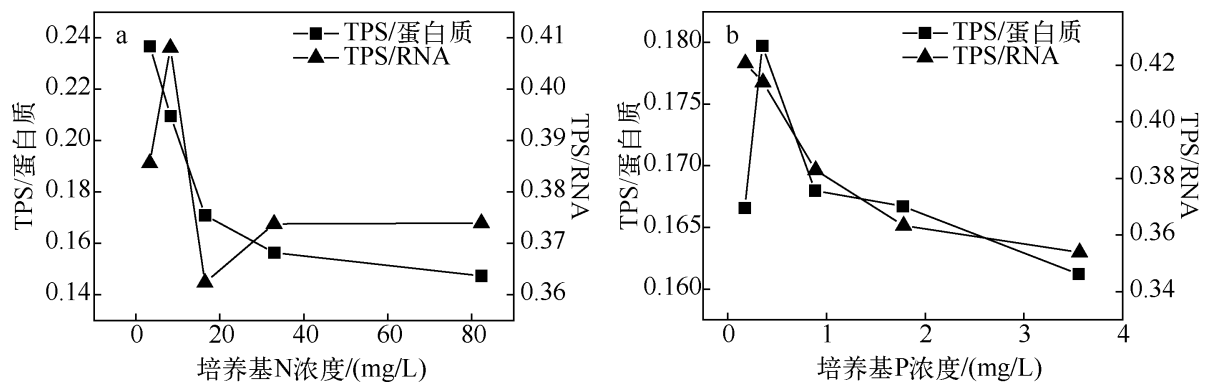

图 $3 \mathrm{~N}$ 组 $(\mathrm{a})$ 和 $\mathrm{P}$ 组 $(\mathrm{b})$ 细胞总糖与蛋白质、RNA 之间的比例关系

Fig. 3 Ratios of TPS to protein and RNA in cells of $\mathrm{N}(\mathrm{a})$ and $\mathrm{P}(\mathrm{b})$ groups

\section{4 三种形态多糖的含量}

$\mathrm{P}$ 组的胞内多糖含量在 $0.38 \sim 0.41 \mathrm{pg} /$ cell 之间, 变化很少; 但是 $\mathrm{N}$ 组的胞内多糖含量从 $0.46 \mathrm{pg} / \mathrm{cell}$ 降至 $0.35 \mathrm{pg} / \mathrm{cell}$, 下降了 $23.81 \%$. N 组的固着性多糖与其胞内多糖有相同的趋势, 但溶解性多糖的趋势相 反. P 组的固着性多糖基本无变化,但溶解性多糖稍有减小 (图 4).

\section{3 讨论}

从实验结果来看, $\mathrm{N}$ 的浓度升高能使单细胞所含蛋白质明显增多, 从 $3.63 \mathrm{pg} / \mathrm{cell}$ 增至 $5.88 \mathrm{pg} / \mathrm{cell}$, 这 与 Downing 等 ${ }^{[12]}$ 以及 Vézie 等 ${ }^{[13]}$ 得出的高 $\mathrm{N}$ 浓度促进微囊藻蛋白质的合成的结论类似, 这种规律在小球 藻、棚藻、㗜藻等藻类中也有发现 ${ }^{[11]}$. 而在实验浓度范围内 $\mathrm{P}$ 对单细胞内蛋白质的含量没有明显的影响.

单细胞中 RNA 的数量相对比较稳定, $\mathrm{P}$ 的增加能使 RNA 有微量的增加, 而 $\mathrm{N}$ 基本上不对 RNA 的含量 


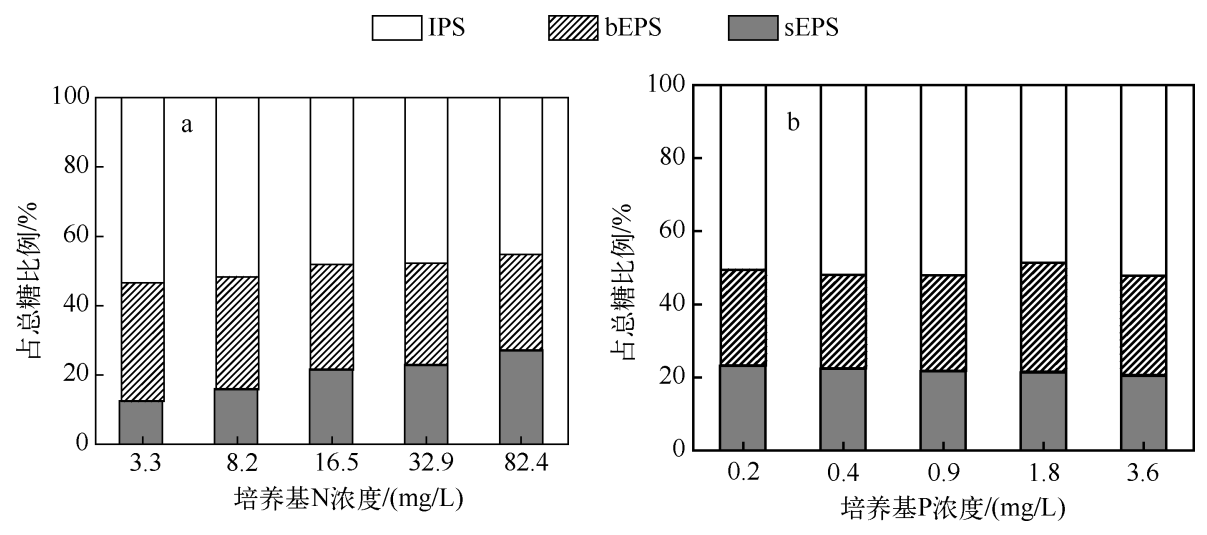

图 $4 \mathrm{~N}$ 组 (a) 和 $\mathrm{P}$ 组 $(\mathrm{b})$ 细胞 3 种形态多糖的含量

Fig. 4 Contents of three patterns of polysaccharide in cells of $\mathrm{N}(\mathrm{a})$ and $\mathrm{P}(\mathrm{b})$ groups

产生影响. P 是合成 RNA 的必需元素, 在实验所设置的最低 P 浓度时, RNA 的合成就已经能满足细胞的生 理需要,因此没有对 RNA 的合成产生制约作用.

无论是 $\mathrm{N}$ 的增加还是 $\mathrm{P}$ 的增加都造成了多糖含量的降低, 这与 $\mathrm{N} 、 \mathrm{P}$ 充足时光合作用的产物优先以蛋白 质、RNA 的形式出现, 而多糖的数量则相对减少有关. 杨州等 ${ }^{[17]}$ 在 2008 年的一篇综述中报道, 在 N 或 P 不 足时, 藻类光合作用固定的有机物质主要以不含 $\mathrm{N} 、 \mathrm{P}$ 的碳水化合物形式存在; 在碳氮代谢不平衡的情况下, 胞外多聚糖充当了接收过剩固定碳的汇. 本实验的结果从另一个方面证实了这一观点, 说明在 N、P 充足条 件下, 藻类光合作用固定的有机物质主要以含有 $N 、 P$ 的碳水化合物形式存在. De Philippis 等 ${ }^{[18]}$ 在 1993 年 的研究中也提出相同观点, 本实验的结果与其一致.

从对微囊藻群体形成的角度来看, 胞外固着性多糖的数量值得关注. N 浓度升高使总糖降低了 $10 \%$, 其 中胞内多糖占总糖的比例降低了 $8.2 \%$, 固着性胞外多糖占总糖的比例降低了 $6.4 \%$, 相反, 溶解性胞外多糖 所占比例却增加了 $14.6 \%$, 溶解性多糖的变化和雷腊梅等 ${ }^{[15]}$ 的研究结果一致. 可以看出, $\mathrm{N}$ 的增加不但降 低了单细胞内多糖的含量, 也改变了细胞中 3 种形态多糖的比例关系, 胞外多糖所占比例从 $46.6 \%$ 增至 $54.8 \%$, 即 $\mathrm{N}$ 的增加促进了多糖向胞外分泌, 并且胞外多糖中溶于水中的比例也增加, 固着性多糖的比例降 低. P 浓度的升高使总糖降低了 $6.1 \%$, 胞内多糖、溶解性胞外多糖和固着性胞外多糖含量虽然出现一些浮 动,但无明显变化趋势, 即 $\mathrm{P}$ 的浓度对多糖形态的影响不太明显.

单细胞中固着性多糖的含量决定了微囊藻细胞的形态, 在微囊藻光合成作用时, $\mathrm{N}$ 促进蛋白质快速合 成, P 能使 RNA 合成略有增加, N、P 充足使微囊藻细胞的繁殖速度加快. 本文 $\mathrm{N}$ 增加可使生长率从 $0.54 \mathrm{~d}^{-1}$ 增加到 $0.57 \mathrm{~d}^{-1}, P$ 增加可使生长率从 $0.51 \mathrm{~d}^{-1}$ 增加到 $0.55 \mathrm{~d}^{-1}$ (图 1), 而野外原位调查及原位培养 ${ }^{[19]}$ 所测 得的原位生长速率一般都低于 $0.20 \mathrm{~d}^{-1}$. 可以推测, 在快速的分裂增殖过程中, 光合作用优先生成 RNA 和蛋 白质, 而作为储能物质的多糖数量则减少, 细胞在多糖合成较少的情况下分裂、繁殖, 造成了单细胞内多糖 含量偏少的结果. 同时, 由于固着性多糖数量不足, 导致培养实验得到的微囊藻很难黏着在一起形成群体形 态, 而是以单细胞的形态出现, 这可能是高生长率培养实验难以培养出群体细胞的原因之一.

\section{4 参考文献}

[ 1 ] Reynolds CS, Jaworski GHM, Cmiech HA et al. On the annual cycle of the blue-green alga Microcystis aeruginosa Kütz. Emend. Elenkin. Philosophical Transactions of the Royal Society of London Series B, Biological Sciences, 1981,293 (1068) : 419-477.

[ 2 ] Bolch CJS, Blackburn SI. Isolation and purification of Australian isolates of the toxic cyanobacterium Microcystis aeruginosa Kütz. Journal of Applied Phycology, 1996, 8: 5-13.

[ 3 ] Wu XD, Kong FX. Effects of light and wind speed on the vertical distribution of Microcystis aeruginosa colonies of different 
sizes during a summer bloom. International Review of Hydrobiology, 2009, 94(3) : 258-266.

[ 4 ] Yang Z, Kong FX, Yang Z et al. Benefits and costs of the grazer-induced colony formation in Microcystis aeruginosa. Annales de Limnologie-International Journal of Limnology, 2009, 45: 203-208.

[ 5 ] Kessel M, Eloff JN. The ultrastructure and development of the colonial sheath of Microcystis marginata. Archives of Microbiology, 1975, 106(3) : 209-214.

[ 6 ] Plude JL, Parker DL, Schommer OJ et al. Chemical characterization of polysaccharide from the slime layer of the cyanobacterium Microcystis flos-aquae C3-40. Applied and Environmental Microbiology, 1991, 57 (6) : 1696-1700.

[ 7 ] De Philippis R, Vincenzini M. Exocellular polysaccharides from cyanobacteria and their possible applications. FEMS Microbiology Reviews, 1998, 22(3): 151-175.

[ 8 ] Yang Z, Kong FX, Shi XL et al. Changes in the morphology and polysaccharide content of Microcystis aeruginosa ( Cyanobacteria) during flagellate grazing. Journal of Phycology, 2008, 44(3) : 716-720.

[ 9 ] Liu Y, Wang W, Zhang M et al. PSII-efficiency, polysaccharide production, and phenotypic plasticity of Scenedesmus obliquus in response to changes in metabolic carbon flux. Biochemical Systematics and Ecology, 2010, 38: 292-299.

[10］张晓峰,孔繁翔,曹焕生等.太湖梅梁湾水华蓝藻复苏过程的研究. 应用生态学报, 2005,16(7):1346-1350.

[11] Piorreck M, Baasch KH, Pohl P. Biomass production, total protein, chlorophylls, lipids and fatty acids of freshwater green and blue-green algae under different nitrogen regimes. Phytochemistry, 1984, 23(2) : 207-216.

[12] Downing TC, Sember CS, Gehringer MM et al. Medium N:P ratios and specific growth rate comodulate microcystin and protein content in Microcystis aeruginosa PCC7806 and M. aeruginosa UV027. Microbial Ecology, 2005, 49 (3): $468-473$.

[13] Vézie C, Rapala J, Vaitomaa J et al. Effect of nitrogen and phosphorus on growth of toxic and nontoxic Microcystis strains and on intracellular microcystin concentrations. Microbial Ecology, 2002, 43(4) : 443-454.

[14] 施军琼,马剑敏,吴忠兴. 环境因子对铜绿微囊藻 7820 胞外多糖的影响. 河南师范大学学报,2008,36(5):120-123.

[15] 雷腊梅, 宋立荣, 欧丹云等. 营养条件对水华蓝藻铜绿微囊藻的胞外多糖产生的影响. 中山大学学报, 2007,46(3): 84-87.

[16] Burkert U, Hyenstrand P, Drakare S et al. Effects of the mixotrophic flagellate Ochromonas sp. on colony formation in $M i$ crocystis aeruginosa. Aquatic Ecology, 2001, 35(1): 9-17.

[17］杨 州,李佳佳. 非生物因素对藻类胞外多聚糖含量影响. 应用生态学报,2008,19(1):198-202.

[18 ] De Philippis R, Margheri MC, Pelosi E et al. Exopolysaccharide production by a unicellular cyanobacterium isolated from a hypersaline habitat. Journal of Applied Phycology, 1993, 5 : 387-394.

[19] 曹焕生,孔繁翔,谭 啸等. 太湖水华蓝藻底泥中复苏和水柱中生长的比较. 湖泊科学, 2006,18(6):585-589. 